\title{
Principles of Professionally-Motivating Training of Students Majoring in "Tourism" and the Rules For Their Implementation in Practice
}

Tatyana B. Lisitzina

Gzhel State Art and Industry Institute, Elektroizolyator, Russia

Email: tat2254@yandex.ru

Yuliya T. Ibatullova

Alfiya A. Mustafina

Volga Region State Academy of Physical Culture, Sport and Tourism, Kazan, Russia

Elvira R. Sadykova

The University of Management "TISBI", Kazan, Russia

Marina B. Kozhanova

Chuvash State Pedagogical University named after I.Y. Yakovlev, Cheboksary, Russia

Albert K. Shaikhlislamov

Venera N. Minsabirova

Kazan Federal University, Kazan, Russia

Doi:10.5901/mjss.2015.v6n2s3p15

\section{Abstract}

The need to study this problem stems from the fact that in a competitive tourism business the problem of competent, professionally-motivated personnel training is actualized for the implementation of this type of activity in modern conditions. To solve this problem in practice, it is necessary to investigate its theoretical foundations. In this context, this paper presents the rationale for the principles of professionally-motivating training of students majoring in "Tourism", and also proposes the rules to implement them in practice. The article contents are valuable both in theoretical and practical terms for university faculty members that train students majoring in "Tourism".

Keywords: professionally-motivating training; principles; students; tourism; practice.

\section{Introduction}

Tourism currently is one of the most rapidly developing sectors of the economy. Travel business in many cases is the initiator and the experimenter in the development and implementation of advanced modern technologies, continually changing the forms and ways of offer and provision of services. In tourism most various innovations are daily introduced under the influence of scientific-technical progress and intellectual development of mankind. Innovation in tourism - is the most important phenomenon contributing to the development of tourism worldwide (Lisitzina et al., 2015; Ilkevich \& Ilkevich, 2013).

A modern tourism specialist should have a good understanding of the innovation processes and skillfully integrate them into his activities. Therefore, the tourism market, which is characterized by a particularly fierce competition, requires highly qualified human resourses, able to adapt to rapidly changing conditions. Ensuring availability of professional education throughout life is the only way of arming people with knowledge and skills, to keep pace with the change of fleeting technologies. The content of professional tourism education should be aimed primarily at a positive change in the 
lives of young people and should guarantee them employment and effective career (Zorin, 2005; Lisitzina et al., 2015). in "Tourism".

This task is achievable through strengthening the professional-motivating component of training students majoring

\section{Literature Review}

In the works of E.P.Ilyin (2002, 2004), M.I.Alekseeva (1990), L.I.Bozhovich (1996), Yu.I.Leonavichus (1975), M.V.Matyukhina (1983), Yu.M.Orlova (1982), V.Hennig (1998), P.M. Jacobson (1998) et al., there are classifications of learning motives, differing both by the number of motives and their qualitative composition. The publications show that, despite the differences in the classifications of motives for learning, all their diversity can be divided into two types - the cognitive and the social.

The effectiveness of learning in a very large extent depends on the content and strength of motivation for learning. In particular, I.P.Podlasy emphasizes that the motivation - is the main factor of success in the educational process. Many psychologists argue that students' successes by about $70 \%$ are definitely due to the motivation; the remaining $30 \%$ are students' abilities (Podlasyy, 2000).

As it is known, one of the main tasks of education - is the formation of such motivational sphere of each person, which would adequately reflect social relations, and the hierarchy of motives would be determined by a harmonious combination of public and individual requirements, when a person wants what is necessary for the society (B.I.Fedorov \& L.M. Perminov (2000), A.S. Makarenko (1992), B.F. Lomov (1984), S.L. Rubinstein (1997)).

Analysis of the survey data allows concluding that the formation of cognitive and professional motivation - is a long process associated with the development of an individual student as a whole, and the transition to a person-focused, truly humane education of students is very difficult in real teaching practice.

\section{Methodological Framework}

The methodological framework in identifying and substantiating the principles of professionally-motivating training of students majoring in "Tourism" consisted in the following provisions.

Formation of professional motivation in training students in the field of tourism is the upbringing and developing: the abilities to set goals for activities and analyze the results; activity and reasonable initiatives aimed at fulfilling obligations; pride in their preparedness, awareness of its high social and personal value; willingness to endure extreme mental and physical exertion; desire to know the requirements of guidance documents; striving to master the content of the training (Ivanov et al., 2015; Shaidullina et al., 2015; Khairullina et al., 2015).

The range of purposes of the professionally-motivating stage of training students majoring in "Tourism" is as follows: to form elements, features of professional motivation of higher levels; ensure mutual transformation of professional motivation and overall motivation of the student; develop a desire for independent learning activities; raise the need for tourist work, focus on the acquired psychophysical qualities as vital for the state (society) and the personality, and so on (Lisitzina et al., 2015).

The objectives of tourism activities on the formation of general and professional motivation include: to cause the students' surprise by an unusual form of event; attract students to assessing and self-assessing their activities; update the professional and general motives by analyzing work-related and life situations; associate general developmental with the professional aspects of the tasks; strengthen professional skills, ensuring the proficiency; provide an opportunity to act independently, engage in collaborative forms of training in the tourism sector; ensure reinforcement of the excited motivational states at past events, to form the focus of the motivation on specific professional activities, and others.

\section{Results and Discussions}

\subsection{Status of the principles of professionally-motivating training of students majoring in "Tourism"}

The principles of professionally-motivating training reflect the laws, the regularities and objectives of professionallymotivating student learning. Consideration of the connections and relationships between the identified principles of professionally-motivating training and the well-known general pedagogical (general methodological) principles of professional education shows that the implementation of one principle is impossible without the others and all together they function and reflect the main features of the student training structure in the field of tourism, which has a professionally-motivating orientation. At that, the principles of professionally-motivating training of students majoring in 
"Tourism" do not duplicate the general methodological principles known, and the need for their introduction is confirmed by not only the needs of the teaching practice itself, but also by the conducted theoretical studies in the field of psychology and pedagogy. The system, including the known and newly formulated principles, gives the teacher a set of instructions (from goal-setting to the results analysis) for organizing the professionally-motivating training of students in groups.

During the research the following principles of professionally-motivating training (PMT) of students majoring in "Tourism" were formulated: the principle of compliance of the training content in the field of tourism in all its elements and at all levels of the designing with the common and disciplinary PMT objectives; the principle of unity of the content and the procedural sides of professional activity; the principle of structural unity of the PMT content at all levels of its formation; the principle of the PMT content focus on implementing the requirements of the qualification profile; the principle of the PMT content correspondence with the content of the main types of a specialist's professional activity.

\subsection{The nature and content of the principles of professionally-motivating training of students majoring in "Tourism"}

The principles of professionally-motivating training of students majoring in "Tourism" are aimed at resolving the following contradictions: between the existing level of professional motives development and the necessary one; between personally and publicly (socially) significant values, needs, goals, interests, et cetera; between the existing motivational attitudes and the functional capabilities of the student.

\subsubsection{The principle of the content compliance with the objectives of professionally-motivating training of students majoring in "Tourism"}

This principle provides for the inclusion in the learning content, except of the traditionally allocated elements (knowledge, abilities, and skills) also those which, in accordance with the personality-based, motivational-value PMT orientation reflect the experience of the creative professional activity and personal attitude to the state, public and universal values. In this case, the priority element of the content is the experience of the emotional-value relation, and the priority types of tourist activities - are the cognitive and the value-oriented. Compliance with this principle requires the implementation in the content-related and procedural PMT aspects of the following ideas: the priority of state (public) interests over personal; priority of the creative over the reproductive, of the valuable over the informational; humanistic orientation as opposed to totalitarian-authoritarian. All these ideas should be considered in the context of forming PM - a personality trait, allowing to consider physical training as public, social and personal value, to ensure unity of the physical training purposes, "center-of-gravity" shift on the emotional and social development of the student.

\subsubsection{The principle of the content-related and procedural unity of professionally-motivating training of students majoring in "Tourism"}

This principle reflects the position of the training experiences in the field of tourism in relation to the theoretical analysis and the composition of its content. It suggests awareness of the teaching reality related to carrying out training in the tourism sector in a particular group, outside of which there cannot exist the training content in the area of tourism. In the curriculums, in teaching aids there should be not only the actual PMT content stated, but also the ways of conveying to students and of their mastering the content. The importance of fulfilling this principle during the tourist activity is due to the fact that the content, methods of updating the tasks performance, the state of the motivational sphere of the actors contribute to the procedural side of the student's motivation, because it is aimed at forming situational motives defined by confluence of external circumstances. Meanwhile, it is known, that only in the case of permanent formation of procedural motivation a discrete-qualitative change across the motivational sphere of the student may occur.

\subsubsection{The principle of structural integrity of the tourist activity content}

The implementation of this principle makes it possible to coordinate and systematize the elements of the PMT content levels. The structural content integrity is maintained when moving from the theoretical levels to the concrete realization of the PMT process. The content cannot be considered as a sum of the generated independently of each other standards, programs, textbooks and manuals, et cetera. As early as at the beginning of their compilation, they must comply with the general idea of the structure, composition and patterns of professionally-motivating college education. This will ensure a unified approach to all teaching and learning materials and their use in tourist work. 


\subsubsection{The principle of the content focus of professionally-motivating training of students majoring in "Tourism" on the implementation of the qualification profile requirements}

This principle emphasizes the necessity for continuous use of a specialist's qualifications as a criterion for the content of training in the field of tourism.

\subsubsection{The principle of the professionally-motivating training of students majoring in "Tourism" content correspondence} with the content of the main types of the specialist's professional activity according to the training profile

This principle points to the need of forming students' general focus and the motives of mastering a particular profession. However, the motivating function of the tourist work content will be implemented only if the motives of general and professional training are not alternative in motivational training of students in the field of tourism, since a teacher's activity is multifaceted and requires a wide range of knowledge and skills.

\subsection{The rules for implementing the principles of professionally-motivating training of students majoring in "Tourism"}

a) when executing the first rule it is necessary to remember that each student majoring in "Tourism" is characterized by varying degrees of general and professional tourist activity motives formation, and the complexity of the teacher's work is that he is faced with many alternatives. What motivation features are necessary to be formed in the first place? What goals of education will be relevant in this group ? How much is general and professional motivation of different students developed ? To set the goals, choose the methods and means of training in the field of tourism the teacher must know the levels of students' professional motivation formation.

b) when implementing the second rule it is necessary to remember that the identification of levels of motivation development is necessary in order to pedagogically reasonably implement a program of upbringing and developing the motivational sphere of students. Knowledge of the levels of motivation development allows not only to record the state of development of socio-psychological qualities of future specialists, but also to set goals of professionally-motivating training in tourism in sequence, providing constant reinforcement and shaping the motives, goals and needs that are the basis for the professional component of the next level tourist motivation.

So, if in a group the majority of the students belong to the first level of professional motivation development in the tourism sector, then the objectives of its formation must be associated primarily with the development of subject-oriented training in tourism field: to inspire by interesting facts, historical examples, to cause the desire to perform simple tasks, to excite the interest for professionally significant elements of training in the tourism sector, to demonstrate the value and necessity of training. It is necessary to excite students' interest in the upcoming tourist activity, to actualize the needs in comprehensive development. The main objective of the transformation is to enrich the content of motivation, the formation of personal and socially-significant training motives, professional needs and aspirations for work in tourism. The main goal of professional motivation formation of the second level students is to develop professional activity motives, to transform common training motives in the field of tourism into professional ones, to form the national and publicly-important motives of improving skills. In this case, more widely projected is the development of the moral content of motivation, focus on mastering the skills of tourist activity. The tasks of educating students in the third level are to develop their ability to set goals of upcoming educational and career-related activities, to enhance interest in general developmental and professional aspects of culture, to ensure mutual transformation of these motives, to form a responsible attitude to their professional duties. As the development objectives of professional motivation of training in the field of tourism in students of the fourth level can be attributed: the upbringing of motives for improving the ways of activity, initiative and independence in setting long-term goals, the aspirations to creativity in educational and professional activities. The objectives of educating students of the fifth level of the PM development are to create conditions for its improvement in the direction of deepening the social and moral content, developing dynamic properties and aspirations for setting the goals of national importance. For students in the sixth level of PM development the training targets in the tourism sector are to support, encourage the existing motivation, create conditions for its further development. In the work of the teacher it is important to raise the prestige of students with high levels of the professional component of training motivation in the tourism sector, so that these trainees were authoritative in the group, and had a 
positive impact on the team;

c) the third rule provides that in the formation of professional motivation of students it is necessary to know and use motivational potentials of components of the training system in the field of tourism (content, methods, tools, organizational forms) during professionally-motivating student training the techniques of implementing relations between the teacher and students should be used. When training in the tourism sector it is useful to adhere to the following rules: to purposefully apply the techniques of forming PM in accordance with the organizational form of training in the tourism sector, its structure, selected methods and forms; to stimulate the activity of mental processes (perception, attention, imagination, feelings, will, passion for sports, and so on); to initiate urgent requirement-motivational states, to constantly support and encourage their development in similar situations; to promote the development of the main components and properties of training motivation in the sphere of tourism;

d) to perform the fourth rule for implementing the principles of professionally-motivating training of students majoring in "Tourism" it is necessary to provide communication of general developmental and applied physical exercises and, consequently, the development of general and professional motives of training in the tourism sector. It requires a deliberate and systematic work, in the process of which it is advisable to use the following methods of forming the motivational sphere: creation of psycho-pedagogical conditions for developing general and professional motives during the context development (improvement in the context of their chosen profession); a continuous account of the relationship of general and professional motives of professional activity as a means of their formation, the efficiency of which is determined by the specifics of the ways of the tourist activity; implementation of the educational function of the continuity principle.

To move a student to a professional activity, it is important to ensure the transformation of the common motives of training in tourism into the professional. With sufficient development of professional motivation the focus in a student's tourist activity shifts from the performed task to the situation of practical and professional actions, while the task itself reflects the content of professional activity in the consciousness of the individual. However, if the professional motives of training in the tourism sector are less developed than the general ones, then such a transformation of motives does not occur. In such a case, the method of forming professional motivation of students should be used, based on the emergence of professional motives as a byproduct of the activity;

e) to perform the fifth rule, it is necessary to provide such insurance of "subject-to-subject interaction of the professional activities members that all teaching techniques of the teacher should correspond to the structure of the motivational bases of the student tourist activity. During this the teacher's activity should be aimed at creating favorable conditions for developing professional motives of training in tourism.

To encourage students to self-setting the professional goals of training in tourism it is required: to explain the purposes to students, as well as the nature and the content of the upcoming activities; inform them what physical and special qualities, applied skills will be formed during the training in tourism, what they should learn; to develop in students the ability to set goals, to encourage initiative, independence; to create problem situations and others.

To develop students' desire to achieve the goal it is necessary: to ensure compliance of the requirements and students' abilities with the professional work; create a sense of autonomy, of self-confidence; to apply supplementary and preparatory exercises; use the combinations of different forms of training in the field of tourism, widely use the recreational and cultural leisure activities, and others.

To reinforce students' confidence in the correctness of their actions, the teacher should: provide assistance only upon request; to organize the operative feedback with clarifications, self-training control, which give the perception of a lack of external control; in accordance with students' wishes to organize mutual aid and collaborative validation of the performed educational training tasks; use estimating, encouraging treatments.

To encourage students to self-evaluation of the professional activity results (development of an emotional attitude to the result), teachers need: to evaluate not only the level of abilities, skills of the students, but also the quality of their professional activity; to use informative treatments in the form of comments, negation, agreement, approval, et cetera; to sum up the work, emphasizing its importance; show pedagogical optimism. In order to focus the student on the professional aspect of training in tourism it is essential: to disclose the practical, social, cultural or other significance of the content of comprehensive training; to show the connection of the professional requirements subject with the achievements of modern science and technology; to rely on the life and work-related experience of the students, their interests and aptitudes; to update and deepen the already learned applied skills, et cetera. 
f) executing the sixth rule provides for timely corrections of the teacher's work, for which systematically, using the summary cards for the state of the professional component of the work motivational sphere and professional excellence, the student motivation is studied, its development is recorded, and accordingly the goals change, as well as the techniques, methods and forms of professionally-motivating training in the tourism sector. The teacher relies on the generated positive elements of professional motivation, aims to develop them. At the same time, it is important for him to neutralize in class the negative motivational states of the students. To make the best instructional decision, it is necessary to continuously review the effectiveness of the applied aids, to compare their motivational features, to take into account the conditions of use.

\section{Conclusion}

Thus, the article disclosed the following principles of professionally-motivating training of students majoring in "Tourism": the principle of compliance of the training content in tourism in all its elements and at all levels of the designing with the general and disciplinary goals of professionally-motivating training; the principle of the unity of the content-related and procedural sides of professional activity; the principle of the structural unity of the professionally-motivating training content at all levels of its formation; the principle of the content focus of professionally-motivating training on implementing the requirements of the qualification profile; the principle of the professionally-motivating training content correspondence with the content of the main types of the specialist professional activity.

These principles have the following requirements to professionally-motivating training of students majoring in "Tourism": professional orientation of the teaching and learning aids; the material should be engaging; compliance of the informative material content with the existing and emerging needs; the availability of the material contents for students; gradual growth in the educational material of new information about special training, in the light of which the previous knowledge and experience can be comprehended and extended to reveal the practical significance in the field of tourism; focus of the material content on developing professional thinking style, dialectical generalization of knowledge in the field of tourism.

\section{References}

Alekseeva M.I. (1990). On the formation of cognitive motives of educational activity. Kiev: Radyanska School, 55-64. Bozhovich L.I. (1996). Psychological patterns of identity formation in ontogenesis. Problems of psychology, 6, 34-44. Fedorov B.I., Perminov L.M. (2000). Some issues of modern didactics. Pedagogy: 3, 18-21.

Henning W. (1998). Lemmotive bei Schülern. Berlin: Volk und Wissen Volkseigener Verlag, 98.

Ilkevich, B. V., \& llkevich, K. B. (2013). Vocational and motivational art-industrial education (p. 204). Gzhel. GGHPI Press.

Ilyin, E. P. (2002). Motivation and motifs (p. 512). Saint Petersburg.

Ilyin, E. P. (2004). Motivation and motives. St. Petersburg.

Ivanov V.G., Shaidullina A.R., Drovnikov A.S., Yakovlev S.A. \& Masalimova A.R. (2015). Regional Experience of Students' Innovative and Entrepreneurial Competence Forming. Asian Social Science, Vol. 11, No. 1, 35-40, doi:10.5539/res.v7n1p35.

Jacobson P.M. (1998). Psychology of emotions and motivation. Moscow, 304.

Khairullina E.R., Valeyev A.S., Valeyeva G.K., Valeyeva N.S., Leifa A.V., Burdukovskaya E.A., Shaidullina A.R. (2015). Features of the Programs Applied Bachelor Degree in Secondary and Higher Vocational Education. Asian Social Science; Vol. 11, No. 3, 213217, doi:10.5539/ass.v11n4p213.

Leonavichus Y. (1975). Time budget of teachers and students, its social conditioning. Kaunas, KPI, 187.

Lisitzina T.B., Kovaleva N.I., Shaikhlislamov A.K., Minsabirova V.N., Shaidullina A.R., Pavlova N.A. \& Nevenchannaya Y.V. (2015). Asian Social Science, Vol. 11, No. 1, 154-158, doi:10.5539/ass.v11n1p154.

Lisitzina T.B., Nikonov V.V., Ilkevich K.B., Ilkevich T.G. \& Masalimova A.R. (2015). The Syllabus of the Regional Component of Professionally Motivational Education Developed for the Students Specializing in Tourism. Asian Social Science, Vol. 11, No. 2, 284-289, doi:10.5539/ass.v11n2p284.

Lisitzina T.B., Pavlova A.V., Khanmurzina R.R., Vlasova V.N., Chitalin N.A., Maksimov I. N. \& V.G. Zakirova. (2015). Features of the Professional and Motivating Training Content Design for Students Majoring in "Tourism". Asian Social Science, Vol. 11, No. 1, 148-153, doi:10.5539/ass.v11n1p148.

Lomov B.F. (1984). Methodological and theoretical problems of psychology. Moscow, Nauka.

Makarenko A.S. (1992). Heritage and contemporary transformation in educational theory and practice Proceedings of the Russian Scientific-Practical Conference. Nizhny Novgorod, 167.

Matyukhina M.V (1983). Study and formation of learning motivation in primary school children. Volgograd, VSPI, 72.

Orlova A.B. (1982). The problem of motivation in foreign social learning theory of personality Motivation. Moscow: APN USSR, 17-29.

Podlasyy I.P. (2000). Pedagogy. New Deal: Proc. for students ped. universities. Moscow, 576.

Rubinstein S.L. (1997). Being and consciousness. Moscow: Publishing House of the USSR Academy of Sciences, 328. 
Shaidullina A.R., Krylov D.A., Sadovaya V.V., Yunusova G.R., Glebov S.O., Masalimova A.R. \& Korshunova I.V. (2015). Model of Vocational School, High School and Manufacture Integration in the Regional System of Professional Education. Review of European Studies, Vol. 7, No. 1, 63-67, doi:10.5539/res.v7n1p63.

Zorin I.V. (2005). Vocational education and careers in tourism. Moscow. 